\title{
PDMS-Based Microfluidic Devices for Cell Culture
}

\author{
Stefania Torino * (1), Brunella Corrado, Mario Iodice ${ }^{(1)}$ and Giuseppe Coppola \\ Institute for Microelectronics and Microsystems, National Research Council, 80131 Naples, Italy; \\ brunella.corrado@na.imm.cnr.it (B.C.); mario.iodice@cnr.it (M.I.); giuseppe.coppola@cnr.it (G.C.) \\ * Correspondence: stefania.torino@na.imm.cnr.it
}

Received: 26 July 2018; Accepted: 4 September 2018; Published: 6 September 2018

\begin{abstract}
Microfluidic technology has affirmed itself as a powerful tool in medical and biological research by offering the possibility of managing biological samples in tiny channels and chambers. Among the different applications, the use of microfluidics for cell cultures has attracted much interest from scientists worldwide. Traditional cell culture methods need high quantities of samples and reagents that are strongly reduced in miniaturized systems. In addition, the microenvironment is better controlled by scaling down. In this paper, we provide an overview of the aspects related to the design of a novel microfluidic culture chamber, the fabrication approach based on polydimethylsiloxane (PDMS) soft-lithography, and the most critical issues in shrinking the size of the system.
\end{abstract}

Keywords: microfluidics; lab-on-a-chip; cell culture

\section{Introduction}

Cell culture plays a key role in cell biology research. Allowing the growth and proliferation of cells in an artificial environment helps provide a better understanding of cell behavior, such as mutation over the time, response to external stimuli (physical or chemical), cell-cell interaction, and so on [1-3]. Traditional in vitro methods for cell culture are nowadays well standardized and allow the growth of most of each type of cell without any issue. However, in the recent years, there has been an increasingly widespread need to find cheaper and less laborious methods. Indeed, in vitro culturing is both expensive, requiring high quantities of samples and reagents, and time consuming, considering the several manual pipetting steps needed. For this reason, the possibility of culturing cells at the microscale is attracting more and more interest among the scientific community. Indeed, microfluidic technology allows for microculture systems to substitute traditional petri dishes and flasks $[4,5]$. Microfluidics was developed more than 20 years ago, and it is usually defined as the science and technology that study the behavior of lesser amounts of liquids $\left(10^{-9}-10^{-18} \mathrm{~L}\right)$ confined in channels with dimensions in the micrometer range (generally tens to a hundred micrometers) [6]. Microfluidic systems are part of a class of miniaturized systems called microelectromechanical systems (MEMS) that are capable of carrying out many functions. In the early 1990s, the concept of lab-on-a-chip (LOC) was introduced [7], with the idea of performing all the reactions and assays traditionally done on a bench in a single microdevice, with the advantage of having better control over the liquids' volume, a significant reduction in sample and reagent costs, and faster processes. Advances in micro and nanofabrication techniques have played a key role in the diffusion of this technology, and researchers from several fields have recognized the great contributions of microfluidic technology. There are several reasons why microfluidics should be used for cell cultures [8-10]. Figure 1 summarizes the main characteristics of microfluidics cell culture approach in comparison with the standard methods. As we already mentioned, culturing cells in a tiny chamber is less expensive since it requires low volumes of samples and reagents. In addition, it allows for better control of the cellular environment. This is important in 
research that focuses on the manipulation of cellular functions and processes obtained by introducing changes in the cellular environment. A successful example of this was proposed several years ago by Luni et al. [11]. In their work, for the first time, they showed how the reprogramming of human somatic cells into induced pluripotent stem cells (hiPSCSCs) can be drastically improved using a microscale approach. The results achieved are easily explained considering the better temporal and spatial control of fluids achievable in microfluidics [12]. More than 10 years ago, Chung et al. produced a chip by which they were able to obtain differentiation and proliferation of neural stem cells. The device was built to have cells subjected to a continuous gradient of grow factors. The stem cells exhibited proliferation and differentiation responses that were concentration dependent in the same way as those seen in parallel control cultures [13]. In another work, the authors proposed a device realized with the aim of controlling the proliferation and stimulating the differentiation of human mesenchymal cells (MSCs) using a chip consisting of 96 individually addressable culture chambers [14].

Besides the optimal spatial and temporal control achievable in microfluidics, it should be considered that small volumes also translate into a reduced number of cells. This is an important aspect, since it allows for the study of small populations of cells and also reaches the single-cell level. Regarding this, in a recent work, Ren et al. [15] developed a microfluidic device in which a variable number of multiconstriction channels were used to differentiate a human breast cancer cell line, MDAMB-231, and a nontumorigenic human breast cell line, MCF-10A. The principle to distinguish between the two cell lines was based on the difference in the mechanical properties exhibited by the cells. Another interesting advantage introduced while working with microfluidic cell cultures is that it is easier to perform single-cell analysis. Indeed, the better control on the cellular microenvironment achieved in these systems introduces a considerable improvement in live-cell imaging analysis. Dynamic phenomena, such as cell movements and migration, cell-cell and cell-extracellular-matrix (ECM) interactions, and subcellular and molecular phenomena, can be detected, with the additional advantage of studying cells in a system that closely mimics the natural microenvironment. In 2013, Tam et al. [16] demonstrated how the existing limitation in super-resolution microscopy, related to the way in which the sample is prepared, can be overcome using microfluidic technology. In that work, first, adherent mammalian cells were introduced and grown in a microfluidic chip under sterile conditions. Then, using an automated fluid-injection device, a precise amount of a specified reagent was delivered to the selected imaging chamber at a specific time during the experiment. In a more recent paper, a microfluidic platform to perform a study of the cellular response to fast oxygen dynamics was proposed [17]. This kind of analysis is quite challenging when using the existing method. However, when using a microfluidic device, the authors were able to get a real-time detection of the reaction of cardiac cultures, both murine and human, to an induced oxygen, glucose, or oxygen/glucose deprivation.

In microfluidic devices, the chemical and physical microenvironment can be easily controlled by using on-chip valves that allow the release of fluids containing target molecules and substances with precise timing [18]. This is particularly of interest to the medical community that focuses on stem cells [19], as reported in the examples presented above. Thanks to the on-chip microvalves, the control of the culture microenvironment can give better results than conventional petri dishes. This ability is also promising for fields such as tissue engineering or cell therapy [20]. In the work of Lanz et al. [21], they provided an example of how microfluidic technology can be a useful tool in studying cell behavior related to a target therapy. The experiment was performed using a commercially available cell culture platform. It allowed the simultaneous culture of 96 perfused microtissues using limited amounts of material, enabling drug screening of patient-derived material. Three-dimensional cell culture viability was improved by constant perfusion of the medium. As a result, triple-negative breast cancer cells were positively attenuated.

Microfluidic cell culture has been shown to lead to an increase in the throughput of different research topics, such as experiments for drug testing [22,23]. Related to this aspect, in recent years, these microtechnology approaches were highly successful not only for 2D but also 3D culture 
models [24-27]. In particular, in the field of three-dimensional culture models, a diffuse approach includes building spheroids of cells. An example of a microfluidic device based on this method was proposed by Zhao et al. [28]. In their work, the authors presented a droplet-based 3D cell culture mode. In this system, a droplet array is attached to the sidewall of a polydimethylsiloxane (PDMS) substrate.
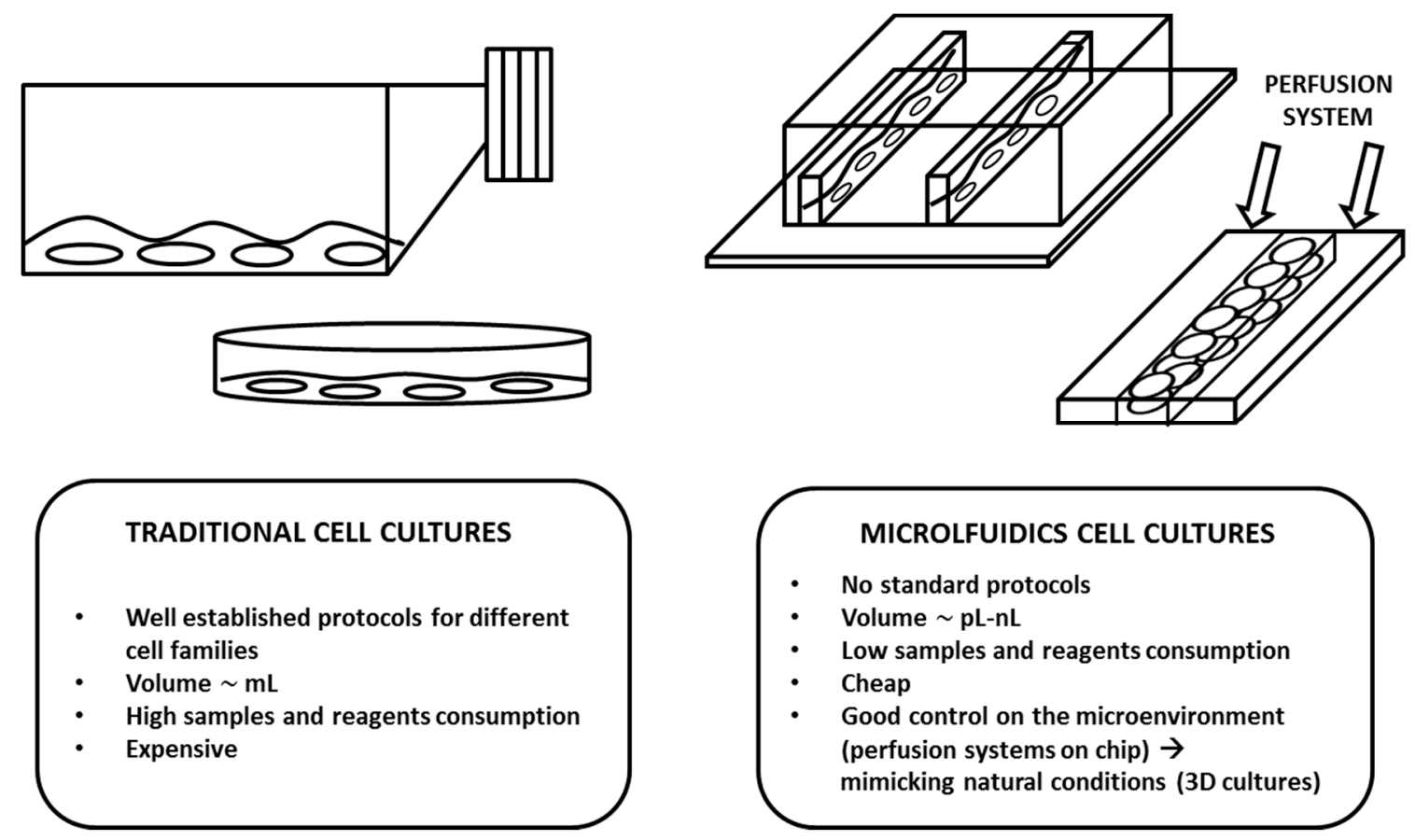

\section{MICROLFUIDICS CELL CULTURES}

- No standard protocols

- Volume $\sim \mathrm{pL}-\mathrm{nL}$

- Low samples and reagents consumption

- Cheap

- Good control on the microenvironment (perfusion systems on chip) $\rightarrow$ mimicking natural conditions (3D cultures)

Figure 1. The schematic gives an idea of the difference between macro and microcell cultures. In the tables below, the figures of the main characteristics of the two different approaches are summarized.

Thus, the PDMS device is a fully automated platform that allows the implementation of a series of cell assay operations, such as droplet generation, drug treatment, cell staining, in situ observation, and direct screening.

The possibility of building three-dimensional cell cultures using microfluidic technology allows also the reconstitution of complex structures and functions of animal and human organs. This research field is known as organs-on-chips [29-31], and the related works suggest that, in the near future, it will be possible to have models that could substitute animal tests with high reliability. Up to now, successful examples of chips mimicking several different organs, such as the lungs, gut, and liver, have been proposed. A few years ago, Huh [32] created a device that could simulate human breathing. This lung-on-a-chip consisted of compartmentalized PDMS microchannels that formed an alveolar-capillary barrier on a thin, porous, flexible PDMS membrane coated with ECM. The system could recreate physiological breathing movements by applying a vacuum to the side chambers, causing mechanical stretching of the PDMS membrane. Another example of organ functions being mimicked at the microscale is the gut model proposed by Kim and Ingber [33]. The revolutionary aspect of the work is that, contrary to the standard culture gut model that consists of a 2D layer of cells, the microdevice was built in order to reproduce the three-dimensional structure and also the behavior of intestinal villi. In this way, cultured cells could be exposed to physiological peristalsis-like motions. Regarding the liver, Bhise et al. [34] devised a liver-on-a-chip model by making hepatic spheroids using a bio-printing technique. Then, the spheroids were cultured on a microfabricated bioreactor consisting of multilayers of PDMS and poly(methyl methacrylate) (PMMA) and included three chambers connected by fluidic channels. Of course, once there are models of every organ, the challenge for the future will be to connect them together and create a system that emulates the whole body in one single chip. 
A key aspect that has to be considered when developing these microfluidic platforms is the need to continuously monitor the cell cultures for metabolic parameters, cell count, or viability, which is essential for achieving a complete characterization of each cell line. This information is needed to establish and ensure reproducible cell cultivations. Despite several advantages of moving cells from macroscopic to microfluidic cell cultures, there are significant differences between the two systems. To compare the behavior of cells at the macro and microscale, these differences must be tracked and analyzed in detail.

Moreover, it is important to continuously monitor the parameters $[35,36]$ that are critical for successful cell proliferation and to keep them alive and in good condition. These parameters are well monitored in traditional cell cultures (consider the available modern incubators and sensors). The main parameters that need to be monitored are [37-40]:

- $\quad$ H-Most normal mammalian cell lines grow well at pH 7.4. However, some transformed cell lines have been shown to grow better in slightly more acidic environments ( $\mathrm{pH} 7.0-7.4)$, and some normal fibroblast cell lines prefer slightly more basic environments ( $\mathrm{pH} 7.4-7.7$ ).

- Dissolved Oxygen (DO)_The dissolved oxygen concentration in culture medium in standard culture conditions is approximately $20-50 \%$.

- Dissolved Carbon Dioxide-A dissolved carbon dioxide level less than $200 \mathrm{mmHg}$ $\left(1 \% \mathrm{CO}_{2}=7.2 \mathrm{mmHg}\right)$ should be generally maintained in cell cultures.

- Temperature-There are optimal temperature values associated with different cell lines. Most human and mammalian cell lines are maintained at $36-37^{\circ} \mathrm{C}$ for optimal growth. Insect cells are cultured at $27^{\circ} \mathrm{C}$ since they grow more slowly at lower temperatures and at temperatures between $27-30{ }^{\circ} \mathrm{C}$; above $30{ }^{\circ} \mathrm{C}$, the viability of insect cells decreases and the cells do not recover even after they are returned to $27^{\circ} \mathrm{C}$. Cell lines derived from cold-blooded animals (e.g., amphibians, cold-water fish) tolerate a wide temperature range between 15 and $26{ }^{\circ} \mathrm{C}$.

Going down to the microscale requires new technologically integrated systems to substitute the ones that fit macrosystems.

Although there are clear advantages introduced by these novel microsystems, it is not trivial to get a cell population comparable to the ones cultivated in the traditional way. However, most of these difficulties can be solved in the design phase. Indeed, microfluidic systems are characterized by great flexibility when designing the device by giving the opportunity to adapt to the application's needs. In the next paragraph, we cover the main physics laws to use when designing a microfluidic cell culture system.

\section{Design and Theory}

When working with miniaturized systems, it is appropriate to consider the scaling effect on the laws of physics. Therefore, the laws of equilibrium of the macrometric world are modified in the micrometric scale. A clear example of this is the fact that gravitational force is negligible compared to capillary force. In designing a new microculture chamber or microreactor, the first thing to understand is the behavior of the fluid flow [41-43]. This is determined by applying the classical equation used in fluid dynamics:

$$
\rho\left(\frac{d v}{d t}+v \cdot \nabla v\right)=-\nabla p+\mu \nabla^{2} v+f
$$

which is the well-known Navier-Stokes equation, written for noncompressible fluid. In this equations, $\rho$ is the fluid density, $v$ the velocity field, $p$ the pressure drop across the channel, $\mu$ the fluid viscosity, and $f$ the volume forces.

Conceptually, the equation can be considered as a balance of the forces acting on each single fluid element:

$$
\overrightarrow{\text { net inertial force }}=\overrightarrow{\text { net pressure force }}+\overrightarrow{\text { net viscous force }}
$$


In most microfluidic devices, the inertial forces are negligible. This means that the previous equation can be simplified as a balance between pressure forces and viscous forces:

$$
\overrightarrow{\text { net pressure force }}=-\overrightarrow{\text { net viscous force }}
$$

In another form:

$$
\nabla p=\mu \nabla^{2} v
$$

The ratio between the inertial and viscous forces defines a dimensionless number that is used in fluid dynamics to characterize the fluid behavior:

$$
R e=\frac{\text { inertial forces }}{\text { viscous forces }}=\frac{\rho v L}{\mu}
$$

where Re is the Reynolds number, which describes if the flow regime is laminar or turbulent. In Equation (4), $L$ is the characteristic length scale of the system. A turbulent flow is chaotic and unpredictable, while laminar flow is a condition in which the velocity of a particle in a fluid stream is not a random function of time. In a laminar flow, all the fluid elements remain parallel to each other. No vortex can generate as usually happens in turbulent flows. Because of the small size of the microchannels, flow is almost always laminar $(R e<2000$, which indicates a laminar flow). The main consequence of laminar flow is that two or more streams flowing in contact with each other will not mix except by diffusion.

In the design of a microculture chamber, it could be interesting to predict how cells spatially distribute in the loading phase. This information can be obtained by coupling the fluid flow with equations that trace the trajectories of particles (or cells) when entering the microchamber.

The problem is solved by applying Newton's second law of motion:

$$
m \frac{d x^{2}}{d t^{2}}=F\left(t, x, \frac{d x}{d t}\right)
$$

where $x$ is the position of the particle, $m$ the particle mass, and $F$ is the sum of all forces acting on the particle. Examples of forces acting on a particle in a fluid are the drag force, the buoyancy force, and the gravity force. The drag force represents the force that a fluid exerts on a particle due to a difference in velocity between the fluid and the particle.

The drag coefficient depends upon the particle characteristics, and so, based on the Reynolds particle number $R e_{p}$ :

$$
R e_{p}=\frac{\left|v-v_{p}\right| 2 r \rho}{\mu}
$$

where $v$ is the velocity of the fluid, $v_{p}$ the particle velocity, $r$ the particle radius, $\rho$ the fluid density, and $\mu$ the fluid dynamic viscosity. The empirical expression for the drag force $F$ is the following one:

$$
F=\pi a^{2} \rho\left|v-v_{p}\right|\left(v-v_{p}\right)\left[1.84 R e_{p}^{-0.31}+0.293 R e_{p}^{0.06}\right]^{3.45}
$$

Microculture platforms for long-term cell culture need a perfusion system [44] to keep the levels of nutrients and other important substances at a desired value. The flowing media create frictional force on the surface of the cells, which is termed as shear stress. The culture chamber should be designed to avoid levels of shear stress that could damage the cell line. Once the velocity field is known, the shear rate can be assessed with the Stokes equation for creeping flow over a sphere:

$$
\tau=\frac{3}{2} \frac{\mu \bar{V}}{R}\left(\frac{R}{r}\right)^{4} \sin \vartheta
$$


where $\tau$ is the shear rate, $\mu$ is the viscosity, $\bar{V}$ is the medium velocity at the cell surface, $R$ is the cell radius, $r$ is the distance from the cell center (in the simplest case $r=R$ ), and $\vartheta$ is the angle between the shear force and the cell surface. From the formula, it is derived that the hydrodynamic shear rate acting on seeded cells has a maximum value at the cell center in the direction of the flow, where $\vartheta=90^{\circ}$.

Another important aspect to consider is how molecules move in cellular environments, both for what is added to the media externally, such as nutrients or drugs, and for substances that are secreted from the cells. In fluid dynamics, the motion of molecules in a fluid can be related mainly to two phenomena: convection and diffusion. Therefore, the competition between convectional flow and diffusion gives rise to two mass transport processes.

Convectional flow tends to move matter in the direction of the flow, whereas diffusion tends to equalize concentration gradients. The Péclet number is a dimensionless number used in fluid dynamics to compare the two tendencies:

$$
P e=\frac{\text { diffusion time }}{\text { convection time }}=\frac{v L}{D}
$$

where $L$ is the distance traveled by the particle: $L \approx v t$ and $L \approx(D t)^{1 / 2}$, respectively, for convection and diffusion. $D$ is the diffusion coefficient.

To estimate the motion of molecules inside the microfluidic culture chamber, the convection and diffusion mass transfer equation must be applied:

$$
\frac{\partial c}{\partial t}+\nabla \cdot(-D \nabla c+c v)=0
$$

where $c$ is the molecule concentration and $v$ is the fluid flow velocity. With the addition of more terms in Equation (10), both the diffusion of the consumption (i.e., oxygen) or production (i.e., $\mathrm{CO}_{2}$ ) of chemical species can be modeled:

$$
\frac{\partial c}{\partial t}+\nabla \cdot(-D \nabla c+c v)=R \cdot \nabla c
$$

where $R$ is the reaction rate. If the target is to predict the oxygen consumption rate, a Michaelis-Menten expression can be used for $R$ :

$$
R_{\mathrm{O}_{2}}=R_{\max , \mathrm{O}_{2}} \frac{c_{\mathrm{O}_{2}}}{c_{\mathrm{O}_{2}}+K_{m m, \mathrm{O}_{2}}}
$$

where $R_{\max , \mathrm{O}_{2}}$ is the maximum oxygen consumption rate and $K_{m m, \mathrm{O}_{2}}$ is the Michaelis-Menten constant corresponding to the oxygen concentration where consumption drops to $50 \%$ of its maximum.

\section{Fabrication of Microfluidic Culture Chambers by PDMS Soft-Lithography}

The development of microfluidic technology and its wide diffusion has gone in parallel with the innovation of techniques used for fabricating these devices. At the beginning, microfluidic devices were fabricated by adopting techniques used in microelectronics. Therefore, the first microfluidic devices were fabricated in silicon and glass. However, to promote the widespread use of microfluidic devices, a faster, less-expensive, and less-specialized method for device fabrication was needed [45]. For instance, for applications in medicine and biology, disposable devices are needed to avoid any type of sample contamination. Most of these needs appeared to be solved with the introduction of polymer materials in microfluidics. Fabrication tools for polymer microdevices [46] are much cheaper than the instruments needed for fabrication in microelectronics. Moreover, the processes for making devices in the semiconductor industry need to be performed in a clean-room environment with expensive facilities that are not easily available for biological or medical laboratories.

All of these challenges are solved with the use of polymer materials. These materials and the fabrication methods of polymer microdevices are cheaper and more affordable. In addition, most of the laboratory items, such as pipette tips, flasks, or culture plates, are made of polymer materials. 
This point also explains the trend toward these materials. Polystyrene (PS) is the most commonly used thermoplastic for cell culture.

There are several different polymers that have been used for fabrication of microfluidic devices, including PMMA [47], polycarbonate (PC) [48], polyvinyl chloride (PVC) [49], polyimide (PI) [50], the family of cyclic olefin polymers (COC) [51], and PS [52].

However, the most widely used polymer for microfluidic applications is PDMS [53-55]. This material is used worldwide for microfluidics, both for academic and industrial applications. This is mainly due to the ease of the fabrication process.

Indeed, PDMS microdevices are fabricated using a process known as elastomeric micromolding, a technique of molding a soft material from a lithographic master, which was developed at Bell Labs in 1974. However, the introduction of PDMS soft-lithography [56] has completely revolutionized the field.

PDMS is a polymer that has a unique combination of properties due to the presence of an inorganic siloxane backbone and organic methyl groups attached to silicon. It is characterized by a very low glass transition temperature and, hence, is fluid at room temperature. This property makes the polymer suitable for the fabrication of microfluidic devices through replica from a stamp.

Hence, the fabrication of PDMS microfluidic devices through soft-lithography consists of two main steps: a photolithography process for the fabrication of the stamp and the molding.

Photolithography is a key process for microelectronics [57]. It consists of lighting through a mask, which is a photosensitive emulsion called photoresist, that has been deposited on a substrate. The stamp, usually referred to as the master mold, can be reused several times.

This means that there is no need for researchers who want to use PDMS to have access to instrumentation for photolithography, which is expensive and requires specialized scientists or technicians. There are several companies or research facilities that can provide a master mold according to the desired requirements. Once you have the master mold, you can proceed in making your polymer device. A schematic of the main steps of the replica molding technique is reported in Figure 2, together with the main characteristics that have contributed to the success of PDMS for biology applications.

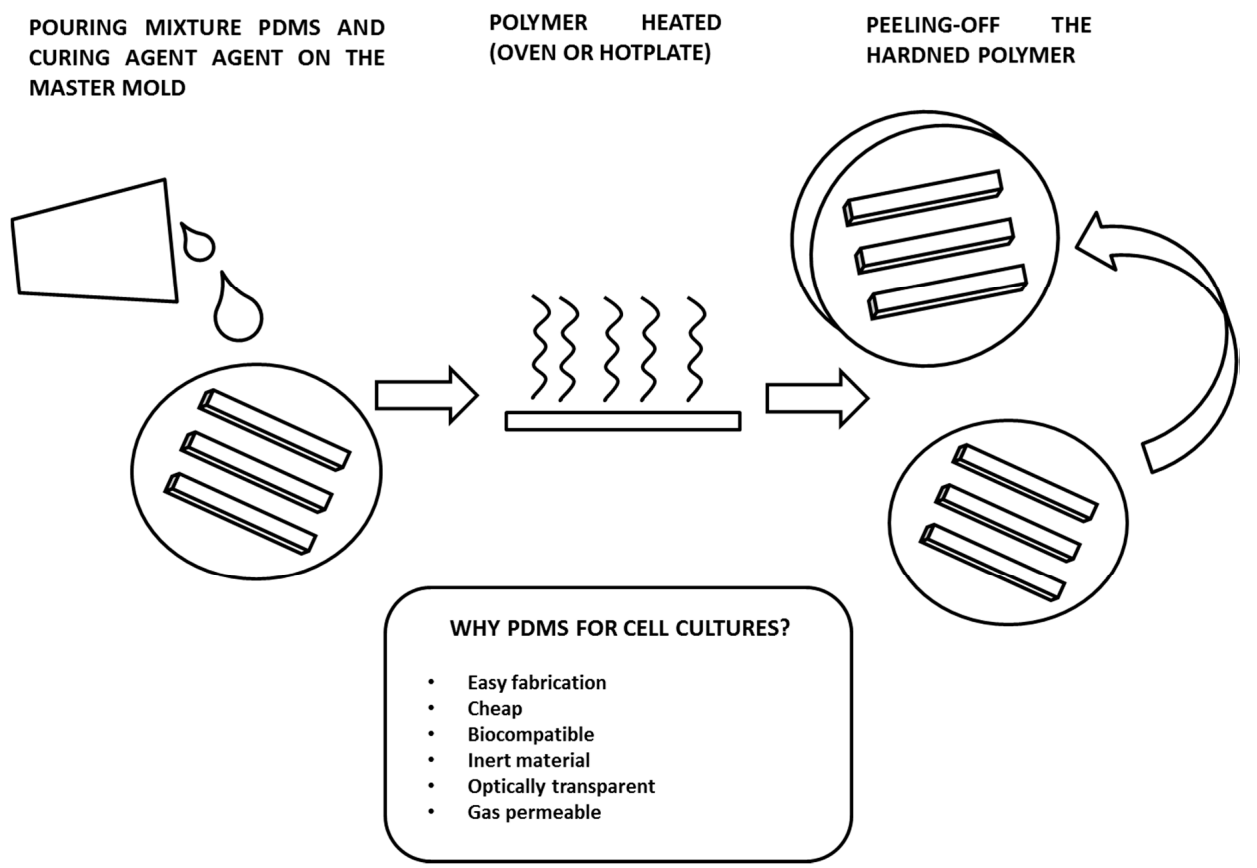

Figure 2. The schematic explains the main steps needed to fabricate a polydimethylsiloxane (PDMS) device using the replica molding technique. The table below the image summarizes the characteristics that have contributed to the wide diffusion of this polymer in cell biology applications. 
The polymer is supplied as a two-part kit: a liquid silicon rubber base and a catalyst or curing agent. By mixing the base with the curing agent, the cross-linking of the polymer chains is activated, and liquid material is converted into solid elastomer. The time needed for ending the process is strongly dependent on the temperature. Indeed, at ambient thermal conditions $\left(20-25^{\circ} \mathrm{C}\right)$, the process can take $72 \mathrm{~h}$. By putting the polymer in an oven or on a hot plate, the common range is $75-100^{\circ} \mathrm{C}$ and the time is reduced to $1-2 \mathrm{~h}$. The obtained device, thanks to the chemical and physical properties of PDMS, can be easily sealed to itself or other substrates both reversibly and irreversibly. The most used approach is to seal PDMS with a glass substrate by exposing the surface of the two materials to $\mathrm{O}_{2}$ plasma and then placing them in contact. These devices are a desirable substrate for 2D cell cultures, although PDMS has also been successfully used for making 3D polymer-based scaffolds as replicas from a 3D printed sacrificial mold [58].

The low cost, fast prototyping, and easy casting procedure are not the only reasons that have made PDMS so popular among the biological community. There are other interesting properties that explain the popularity gained by this polymer [59]:

- Optical transparency. PDMS is optically transparent from a 240-1100 nm wavelength and is therefore compatible with many optical detection methods. Although PDMS is optically transparent, it has an intrinsic fluorescence, with intensity values smaller than the ones given by other polymers, that is considerably lower than the signals from fluorescence measurements performed on cells. If the PDMS microculture chamber is sealed with a glass slide using an inverted microscope with acquisition in reflection, the fluorescence from the polymer will be a weak signal on the background. However, for some applications, diffraction and reflection of light waves through the material could be a problem, for example, when the detection of fluorescent reporters within the growth chamber should be correlated with gene expression or molecular binding events [60].

- Gas permeability. PDMS is gas permeable and therefore a perfect material for cell cultures, since it allows the control of the amount of gas through the exchange across the polymer matrix [61]. The concentration of $\mathrm{O}_{2}$ and $\mathrm{CO}_{2}$ can be kept in the required range for good cell viability. This is a critical issue especially when these microsystems are to be used for establishing long-term cultures (i.e., days or weeks). On the other hand, the gas permeability of PDMS can introduce some issues, such as the evaporation of the media. This aspect strongly affects cell cultures in microchambers due the small quantity of liquid samples (in the order of few microliters). Evaporation leads to bubble formation, which consequently lyses the cells in the chamber. Several solutions have been proposed to overcome this issue, such as: insuring a sufficient humidity level in the incubator in which the microculture chambers are placed [62]; using a large-volume reservoir filled with the culture media to compensate the rate of evaporation [63]; and coating the PDMS channel with a polymer layer, usually parylene, to prevent evaporation [64].

- Inert material. Inert surfaces are of great interest since they allow the spatial patterning of proteins or cells. The most commonly used technique for making these patterned substrates is microcontact printing [65]. An elastomeric PDMS stamp is first inked with a solution containing the patterning component, and then the stamp is brought into physical contact with the target surface. This can be another PDMS layer or a substrate of a different material, such as a metal or glass. With this technique, cells are well confined to a specific region of a substrate, allowing the precise control of the size and shape of the cell population. This approach is quite widely used in applications for tissue engineering or bio-sensing [66,67].

- Biocompatibility. This is the most important requirement for a material that interfaces with biological samples. It can be defined as the property by which the material does not produce undesirable effects on a biological organism [68]. In medicine and biology, there had been a tendency to use natural polymers or modified natural polymers. However, nowadays, there are many synthetic polymers that are widely used for bio-applications, such as polylactic acid (PLA) and polyglycolic acid (PGA), which are the most used materials for scaffold fabrication in tissue 
engineering. PDMS is highly biocompatible. Several studies have demonstrated the success of using the polymer for the fabrication of microdevices for cell cultures, for organ-on-chip models, and for making implantable devices or parts of them. In some cases, issues related to the compatibility of devices made of other materials, i.e., having metal parts, have been solved by covering them with a PDMS film [69].

All these intrinsic PDMS properties make it an appropriate choice of polymer for cell culture applications. In addition, the ease of prototyping allows for the design, molding, and fabrication of microfluidic systems with several advantages over macroscopic systems. Indeed, active elements, such as sensors or continuous perfusion systems, are easily integrated. Systems capable of good control over the cellular microenvironment can be realized by sustaining a variety of cell types and also integrating real-time data acquisition at single-cell resolution.

\section{Discussions and Conclusions}

Cell culture is a fundamental step for modern medical, biological, and pharmaceutical research. Nowadays, laboratories use culture methods that have been established over a century of work. Despite the satisfactory results obtained through these traditional techniques, scientists have been attracted by the possibility of moving to the microscale. Microfluidic technology has shown great potential for the fabrication of advanced cell culture models. Several microdevices for two-dimensional and biological in vivo-like three-dimensional cultures have been developed.

The increased use of this technology can be explained by considering the advantages introduced by going down at the microscale. Among these, the most significant ones are the ease of cell handling and of patterning molecules and cells and the better temporal and spatial environmental control. Besides these aspects, the rapid diffusion of cell culture microfluidics has also been also supported by the availability of an easy, cheap, and fast prototyping fabrication method, namely, soft-lithography. This technique allows the shaping of soft polymer materials by using a rigid mold; hence, multiple replicas can be obtained. The most used polymer in microfluidics is PDMS, since it has several attractive properties that make it suitable as a material for devices capable of supporting a wide range of applications. Some of these characteristic features have made it attractive to researchers in cell biology.

In the last two decades, many examples of microfluidic platforms for cell cultures have demonstrated how these microsystems can be successfully adopted in substitution of the traditional macroscale approach. However, this field is still in its initial phase, and more data are needed to have a complete understanding of the multiple aspects and characteristics of the cell environment at the microscale. Indeed, despite the advantages that are introduced, there are several challenges to deal with in the transition from macroscopic to microfluidic cell cultures [8]. Many assumptions that are true for conventional in vitro culture methods may no longer be valid.

The first analysis that should be done is considering the lower volume, usually in the order of a few microliters, and the lower surface area of a microculture chamber. The critical parameter is the surface-to-volume ratio. The value is fixed when working with traditional culture methods, and it is roughly $0.5 \mathrm{~mm}^{2}$ to $1 \mu \mathrm{L}$ of medium, which is valid from the smallest 96 -well plates to the biggest flasks.

For microfluidic devices, this standardization is not directly straightforward, since the surface-to-volume ratio varies from one microfluidic device to another. Usually, the average value is significantly higher compared to conventional culture plates, flasks, or dishes. As a consequence, changes in cell proliferation and metabolism are induced. This leads both to a faster consumption of nutrients from the media and to a faster accumulation of waste products. For this reason, it is necessary to integrate the microculture devices with perfusion systems for media renewal, especially for long-term cultures. It has been estimated that the concentration of important nutrients within a microdevice drops after three days, leading to cell death, but a renewal of media leads to longer cell 
viability [70]. On the other hand, the continuous change of the microenvironment could be a strong limit for some research fields, such as those focused on studying cell signaling or drug-dose response.

Other issues that have been raised are related to the surface properties of PDMS. As we reported in this paper, this is the most used polymer for microfluidic cell culture, since has properties that make it suitable for these applications, such as high biocompatibility and gas permeability. However, some works have shown how some uncross-linked monomers may move from the polymer to the medium and interact with hydrophobic parts of the cell membrane [70]. A reverse consideration should be done if we consider that PDMS is hydrophobic and could induce the absorption of several small and hydrophobic molecules involved in cell microenvironments [71]. This effect needs to be well characterized, since among these hydrophobic molecules, there are also lipids that are the fundamental source of energy for cells.

In conclusion, we can affirm that the research that has been performed till now in this field has clearly demonstrated how microfluidic culture systems have the potential to become a substitute for traditional macroscale techniques. Several examples of microfluidic cultures for different cell typologies have been successfully realized. However, there is still much work to be done before these microsystems are adopted into widespread practice. Biologists expect high reproducibility, but microfluidics still encounters technical problems when attempting to meet such requirements. Therefore, there is a need to understand which macroscale assumptions are still true when the culture is scaled down and to develop ad hoc culture protocols for the microscale. Further, despite the advantages introduced by using microtechnology approaches, such as reductions in sample and reagent consumption or improvements in spatial and temporal control over the culture, there are complexities added by adopting this method. For instance, it is not straightforward for scientists or technicians who are well trained on standard cell culture procedures to move to microfluidic platforms. First, intensive training on how to pipette in the inlet microwells is needed. The operator needs to avoid the introduction of air or the formation of bubbles while loading the sample into the chamber. Indeed, it is well known that air is one of the worst enemies of cells. As soon as they come into contact with air for too long, cells dehydrate and die. So, the introduction of air in the microfluidic channel has to be avoided. Indeed, once a small air bubble is introduced, it starts to grow or nucleate with the other small bubbles that are nearby. Therefore, it is important to avoid this from the starting, since once they are formed, it is difficult to remove them, and the process may be pointless if the biological sample is already damaged. At that point, it would be better to not use that microchannel for future experiments. Besides avoiding air introduction into the channel, it is crucial to not be too fast while loading the cells into the microfluidic chamber. Indeed, due to the small size of the channel, cells could undergo a considerably high shear rate. This must be avoided, since if the stress is too high, even if cells stay alive, they could undergo some transformations that could alter their shape, growth, nutrient consumption, or interaction with the other cells in the culture. This means that in every future experiment, the obtained results or information would not be reliable and could not be compared with the data acquired from observing cell behavior in traditional cell cultures. Both of the abovementioned aspects are tricky, since they are not encountered while working with flasks or petri dishes. This means that before using microfluidic culture systems, operators must undergo extensive training in order to ensure correctness of the operations and to guarantee high reproducibility and reliability in the performed experiments. The complexity of daily operations—which could be addressed by improving the technology [72,73] by making more automated devices, such as by introducing actuators for liquid control or sensors for monitoring key parameters-can explain why the adoption of this system in standard practice has been slow. Development and standardization can take several years, but the more difficult point is the beginning, since it is not easy to convince people that have always been operating with certain protocols to move to something new, especially if this requires more training and can cause failures due to lack of experience. Regardless, the attraction to microfluidic cell cultures is increasing year by year. Even if the presented examples are mostly related to stand-alone research 
projects and not to the use of this technology for daily practice as a substitute for the macro approach, they can stimulate interest and curiosity and can dispose people toward that direction.

However, it must be stressed that the more significant contributions of microtechnology are expected to be not in the area focused on reducing the size of standard macro cell cultures, but in the possibility of realizing complex 3D microenvironments that are not achievable with the standard methods. In particular, the possibility of mimicking microvasculature has been recently demonstrated [74]. Having a system like this available for all research laboratories will have a great impact on research focused on understanding the behavior of blood cells while flowing in vessels or the way in which they interact with the endothelium, both when they are in normal or pathologic states. Also, the organ-on-a-chip research field has great promise. The successful operation of microfluidic models mimicking the function of vital organs has been demonstrated by several researchers [75]. Considering all of these aspects, it is not difficult to imagine that, in the near future, these systems will become a key part of biological research, in particular, considering the great contributions that they can provide for drug discovery and testing.

Conflicts of Interest: The authors declare no conflict of interest.

\section{References}

1. Bergmann, S.; Steinert, M. Chapter One-From Single Cells to Engineered and Explanted Tissues: New Perspectives in Bacterial Infection Biology. Int. Rev. Cell Mol. Biol. 2015, 319, 1-44. [CrossRef] [PubMed]

2. Mather, J.P. (Ed.) Cell Culture Studies Using Extracts of Extracellular Matrix to Study Growth and Differentiation in Mammalian Cells. In Mammalian Cell Culture; Springer: Boston, MA, USA, 1984; ISBN 978-1-4615-9361-4.

3. Michael Conn, P. (Ed.) Laboratory Methods in Cell Biology: Biochemistry and Cell Culture, 11st ed.; Elsevier Academic Press: Cambridge, UK, 2012; Volume 112, ISBN 9780124055490.

4. Sackmann, E.K.; Fulton, A.L.; Beebe, D.J. The present and future role of microfluidics in biomedical research. Nature 2014, 507, 181-189. [CrossRef] [PubMed]

5. Beebe, D.J.; Mensing, A.J.; Walker, G.M. Physics and applications of microfluidics in biology. Annu. Rev. Biomed. Eng. 2002, 4, 261-286. [CrossRef] [PubMed]

6. Whitesides, G.M. The origins and the future of microfluidics. Nature 2006, 442, 368-373. [CrossRef] [PubMed]

7. Abgrall, P.; Gué, A.M. Lab-on-chip technologies: Making a microfluidic network and coupling it into a complete microsystem-A review. J. Micromech. Microeng. 2007, 17, R15-R49. [CrossRef]

8. Halldorsson, S.; Lucumi, E.; Gómez-Sjöberg, R.; Fleming, R.M.T. Advantages and challenges of microfluidic cell culture in polydimethylsiloxane devices. Biosens. Bioelectron. 2015, 63, 218-231. [CrossRef] [PubMed]

9. Young, E.W.K.; Beebe, D.J. Fundamentals of microfluidic cell culture in controlled microenvironments. Chem. Soc. Rev. 2010, 39, 1036-1048. [CrossRef] [PubMed]

10. Mehling, M.; Tay, S. Microfluidic Cell Culture. Curr. Opin. Biotechnol. 2014, 25, 95-102. [CrossRef] [PubMed]

11. Luni, C.; Giulitti, S.; Serena, E.; Ferrari, L.; Zambon, A.; Gagliano, O.; Giobbe, G.G.; Michielin, F.; Knöbel, S.; Bosio, A.; et al. high-efficiency cellular reprogramming with microfluidics. Nat. Methods 2016, 13, 446-452. [CrossRef] [PubMed]

12. Novo, P.; Dell'Aica, M.; Janasek, D.; Zahedi, R.P. High spatial and temporal resolution cell manipulation techniques in microchannels. Analyst 2016, 141, 1888-1905. [CrossRef] [PubMed]

13. Chung, B.G.; Flanagan, L.A.; Rhee, S.W.; Schwartz, P.H.; Lee, A.P.; Monuki, E.S.; Jeon, N.L. Human neural stem cell growth and differentiation in a gradient-generating microfluidic device. Lab Chip 2005, 5, 401-406. [CrossRef] [PubMed]

14. Gómez-Sjöberg, R.; Leyrat, A.A.; Pirone, D.M.; Chen, C.S.; Quake, S.R. Versatile, fully automated, microfluidic cell culture system. Anal. Chem. 2007, 79, 8557-8563. [CrossRef] [PubMed]

15. Ren, X.; Ghassemi, P.; Babahosseini, H.; Strobl, J.S.; Agah, M. Single-Cell Mechanical Characteristics Analyzed by Multiconstriction Microfluidic Channels. ACS Sens. 2017, 2, 290-299. [CrossRef] [PubMed]

16. Tam, J.; Cordier, G.A.; Balint, S.; Sandoval Alvarez, A.; Borbely, J.S.; Lakadamyali, M. A Microfluidic Platform for Correlative Live-Cell and Super-Resolution Microscopy. PLoS ONE 2014, 9, e115512. [CrossRef] [PubMed] 
17. Martewicz, S.; Gabrel, G.; Campesan, M.; Canton, M.; di Lisa, F.; Elvassore, N. Live Cell Imaging in Microfluidic Device Proves Resistance to Oxygen/Glucose Deprivation in Human Induced Pluripotent Stem Cell-Derived Cardiomyocytes. Anal. Chem. 2018, 90, 5687-5695. [CrossRef] [PubMed]

18. Jovic, A.; Howell, B.; Takayama, S. Timing is everything: Using fluidics to understand the role of temporal dynamics in cellular systems. Microfluid. Nanofluid. 2009, 6, 717-729. [CrossRef]

19. Kamei, K.; Guo, S.; Yu, Z.T.F.; Takahashi, H.; Gschweng, E.; Suh, C.; Wang, X.; Tang, J.; McLaughlin, J.; Witte, O.N.; et al. An integrated microfluidic culture device for quantitative analysis of human embryonic stem cells. Lab Chip 2009, 9, 555-563. [CrossRef] [PubMed]

20. Khademhosseini, A.; Langer, R. A decade of progress in tissue engineering. Nat. Protoc. 2016, 11, $1775-1781$. [CrossRef] [PubMed]

21. Lanz, H.L.; Saleh, A.; Kramer, B.; Cairns, J.; Ng, C.P.; Yu, J.; Trietsch, S.J.; Hankemeier, T.; Joore, J.; Vulto, P.; et al. Therapy response testing of breast cancer in a $3 \mathrm{D}$ high-throughput perfused microfluidic platform. BMC Cancer 2017, 17, 709-719. [CrossRef] [PubMed]

22. Dittrich, P.S.; Manz, A. Lab-on-a-chip: Microfluidics in drug discovery. Nat. Rev. Drug Discov. 2006, 5, 210-218. [CrossRef] [PubMed]

23. Mattern, K.; Beißner, N.; Reichl, S.; Dietzel, A. DynaMiTES-A dynamic cell culture platform for in vitro drug testing PART 1-Engineering of microfluidic system and technical simulations. Eur. J. Pharm. Biopharm. 2018, 126, 159-165. [CrossRef] [PubMed]

24. van Duinen, V.; Trietsch, S.J.; Joore, J.; Vulto, P.; Hankemeier, T. Microfluidic 3D cell culture: From tools to tissue models. Curr. Opin. Biotechnol. 2015, 35, 118-126. [CrossRef] [PubMed]

25. Sung, K.E.; Beebe, D.J. Microfluidic 3D models of cancer. Adv. Drug Deliv. Rev. 2014, 79-80, 68-78. [CrossRef] [PubMed]

26. Wu, J.; Chen, Q.; Liu, W.; He, Z.; Lin, J.M. Recent advances in microfluidic 3D cellular scaffolds for drug assays. TrAC Trends Anal. Chem. 2017, 87, 19-31. [CrossRef]

27. Park, D.H.; Jeon, H.J.; Kim, M.J.; Nguyen, X.D.; Morten, K.; Go, J.S. Development of a microfluidic perfusion 3D cell culture system. J. Micromech. Microeng. 2018, 28, 045001. [CrossRef]

28. Zhao, S.P.; Ma, Y.; Lou, Q.; Zhu, H.; Yang, B.; Fang, Q. Three-Dimensional Cell Culture and Drug Testing in a Microfluidic Sidewall-Attached Droplet Array. Anal. Chem. 2017, 89, 10153-10157. [CrossRef] [PubMed]

29. Huh, D.; Hamilton, G.A.; Ingber, D.E. From 3D cell culture to organs-on-chips. Trends Cell Biol. 2011, 21, 745-754. [CrossRef] [PubMed]

30. Bhatia, S.N.; Ingber, D.E. Microfluidic organs-on-chips. Nat. Biotechnol. 2014, 32, 760-772. [CrossRef] [PubMed]

31. Vickerman, V.; Blundo, J.; Chung, S.; Kamm, R. Design, fabrication and implementation of a novel multi-parameter control microfluidic platform for three-dimensional cell culture and real-time imaging. Lab Chip 2008, 8, 1468-1477. [CrossRef] [PubMed]

32. Huh, D. A Human Breathing Lung-on-a-Chip. Ann. Am. Thorac. Soc. 2015, 12, S42-S44. [CrossRef] [PubMed]

33. Kim, H.J.; Ingber, D.E. Gut-on-a-Chip microenvironment induces human intestinal cells to undergo villus differentiation. Integr. Biol. 2013, 5, 1130-1140. [CrossRef] [PubMed]

34. Bhise, N.S.; Manoharan, V.; Massa, S.; Tamayol, A.; Ghaderi, M.; Miscuglio, M.; Lang, Q.; Zhang, Y.S.; Shin, S.R.; Calzone, G.; et al. A liver-on-a-chip platform with bioprinted hepatic spheroids. Biofabrication 2016, 8, 014101. [CrossRef] [PubMed]

35. Weltin, A.; Slotwinski, K.; Kieninger, J.; Moser, I.; Jobst, G.; Wego, M.; Ehret, R.; Urban, G.A. Cell culture monitoring for drug screening and cancer research: A transparent, microfluidic, multi-sensor microsystem. Lab Chip 2014, 14, 138-146. [CrossRef] [PubMed]

36. Jeevarajan, A.S.; Vani, S.; Taylor, T.D.; Anderson, M.M. Continuous $\mathrm{pH}$ monitoring in a perfused bioreactor system using an optical pH sensor. Biotechnol. Bioeng. 2002, 78, 467-472. [CrossRef] [PubMed]

37. Gao, F.G.; Jeevarajan, A.S.; Anderson, M.M. Long-term continuous monitoring of dissolved oxygen in cell culture medium for perfused bioreactors using optical oxygen sensors. Biotechnol. Bioeng. 2004, 86, 425-433. [CrossRef] [PubMed]

38. Pattison, R.N.; Swamy, J.; Mendenhall, B.; Hwang, C.; Frohlich, B.T. Measurement and control of dissolved carbon dioxide in mammalian cell culture processes using an in situ fiber optic chemical sensor. Biotechnol. Prog. 2000, 16, 769-774. [CrossRef] [PubMed] 
39. Naciri, M.; Kuystermans, D.; Al-Rubeai, M. Monitoring pH and dissolved oxygen in mammalian cell culture using optical sensors. Cytotechnology 2008, 57, 245-250. [CrossRef] [PubMed]

40. Tabeling, P. Introduction to Microfluidics, 6th ed.; Oxford University Press: New York, NY, USA, 2005.

41. Bruus, H. Theoretical Microfluidics; Oxford University Press Inc.: New York, NY, USA, 2008.

42. Nguyen, N.T.; Wereley, S.T. Fundamental and Applications of Microfluidics, 2nd ed.; Artech House: Norwood, MA, USA, 2002.

43. Kim, L.; Toh, Y.C.; Voldman, J.; Yu, H. A practical guide to microfluidic perfusion culture of adherent mammalian cells. Lab Chip 2007, 7, 681-694. [CrossRef] [PubMed]

44. Ren, K.; Zhou, J.; Wu, H. Materials for Microfluidic Chip Fabrication. Acc. Chem. Res. 2013, 46, $2396-2406$. [CrossRef] [PubMed]

45. Becker, H.; Gärtner, C. Polymer microfabrication technologies for microfluidic systems. Anal. Bioanal. Chem. 2008, 390, 89-111. [CrossRef] [PubMed]

46. Hong, T.F.; Ju, W.J.; Wu, M.C.; Tai, C.H.; Tsai, C.H.; Fu, L.M. Rapid prototyping of PMMA microfluidic chips utilizing a $\mathrm{CO}_{2}$ laser. Microfluid. Nanofluid. 2010, 9, 1125-1133. [CrossRef]

47. Shadpour, H.; Hupert, M.L.; Patterson, D.; Liu, C.; Galloway, M.; Stryjewski, W.; Goettert, J.; Soper, S.A. Multichannel Microchip Electrophoresis Device Fabricated in Polycarbonate with an Integrated Contact Conductivity Sensor Array. Anal. Chem. 2007, 79, 870-878. [CrossRef] [PubMed]

48. Pugmire, D.L.; Waddell, E.A.; Haasch, R.; Tarlov, M.J.; Locascio, L.E. Surface Characterization of Laser-Ablated Polymers Used for Microfluidics. Anal. Chem. 2002, 74, 871-878. [CrossRef] [PubMed]

49. Metz, S.; Holzer, R.; Renaud, P. Polyimide-based microfluidic devices. Lab Chip 2001, 1, 29-34. [CrossRef] [PubMed]

50. Steigert, J.; Haeberle, S.; Brenner, T.; Muller, C.; Steinert, C.P.; Koltay, P.; Gottschlich, N.; Reinecke, H.; Ruhe, J.; Zengerle, R.; et al. Rapid prototyping of microfluidic chips in COC. J. Micromech. Microeng. 2007, 17, 333-341. [CrossRef]

51. Young, E.W.K.; Berthier, E.; Guckenberger, D.J.; Sackmann, E.; Lamers, C.; Meyvantsson, I.; Huttenlocher, A.; Beebe, D.J. Rapid Prototyping of Arrayed Microfluidic Systems in Polystyrene for Cell-Based Assays. Anal. Chem. 2011, 83, 1408-1417. [CrossRef] [PubMed]

52. McDonald, J.C.; Duffy, D.C.; Anderson, J.R.; Chiu, D.T.; Wu, H.; Schueller, O.J.; Whitesides, G.M. Fabrication of microfluidic systems in poly(dimethylsiloxane). Electrophoresis 2000, 21, 27-40. [CrossRef]

53. Fujii, T. PDMS-based microfluidic devices for biomedical applications. Microelectron. Eng. 2002, 61-62, 907-914. [CrossRef]

54. Hongbin, Y.; Guangya, Z.; Siong, C.F.; Shouhua, W.; Feiwen, L. Novel polydimethylsiloxane (PDMS) based microchannel fabrication method for lab-on-a-chip application. Sens. Actuator B-Chem. 2009, 137, 754-761. [CrossRef]

55. Xia, Y.; Whitesides, G.M. Soft lithography. Annu. Rev. Mater. Sci. 1998, 28, 153-184. [CrossRef]

56. Mack, C. Introduction to Semiconductor Lithography. In Fundamental Principles of Optical Lithography: The Science of Microfabrication; John Wiley \& Sons, Ltd.: Hoboken, NJ, USA, 2007; ISBN 978-0-470-01893-4.

57. Mohanty, S.; Larsen, L.B.; Trifol, J.; Szabo, P.; Burri, H.V.R.; Canali, C.; Dufva, M.; Emnéus, J.; Wolff, A. Fabrication of scalable and structured tissue engineering scaffolds using water dissolvable sacrificial 3D printed moulds. Mater. Sci. Eng. C 2015, 55, 569-578. [CrossRef] [PubMed]

58. Mata, A.; Fleischman, A.J.; Roy, S. Characterization of Polydimethylsiloxane (PDMS) Properties for Biomedical Micro/Nanosystems. Biomed. Microdevices 2005, 7, 281-293. [CrossRef] [PubMed]

59. Ng, W. Transparent PET optical window for microfluidic cell culture device. PeerJ Prepr. 2017, 5, e3245v1. [CrossRef]

60. Merkel, T.C.; Bondar, V.I.; Nagai, K.; Freeman, B.D.; Pinnau, I. Gas sorption, diffusion, and permeation in poly(dimethylsiloxane). J. Polym. Sci. B Polym. Phys. 2000, 38, 415-434. [CrossRef]

61. Christen, J.B.; Andreou, A.G. Design, Fabrication, and Testing of a Hybrid CMOS/PDMS Microsystem for Cell Culture and Incubation. IEEE Trans. Biomed. Circuits Syst. 2007, 1, 3-18. [CrossRef] [PubMed]

62. Zhu, X.; Chu, L.Y.; Chueh, B.; Shen, M.; Hazarika, B.; Phadke, N.; Takayama, S. Arrays of horizontally-oriented mini-reservoirs generate steady microfluidic flows for continuous perfusion cell culture and gradient generation. Analyst 2004, 129, 1026-1031. [CrossRef] [PubMed]

63. Flueckiger, J.; Bazargan, V.; Stoeber, B.; Cheung, K.C. Characterization of postfabricated parylene C coatings inside PDMS microdevices. Sens. Actuators B Chem. 2011, 160, 864-874. [CrossRef] 
64. Ruiz, S.A.; Chen, C.S. Microcontact printing: A tool to pattern. Soft Matter 2007, 3, 168-177. [CrossRef]

65. Bernard, A.; Delamarche, E.; Schmid, H.; Michel, B.; Bosshard, H.R.; Biebuyck, H. Printing patterns of proteins. Langmuir 1998, 14, 2225-2229. [CrossRef]

66. Andersson, H.; van den Berg, A. Microfabrication and microfluidics for tissue engineering: State of the art and future opportunities. Lab Chip 2004, 4, 98-103. [CrossRef] [PubMed]

67. Williams, D.F. On the mechanisms of biocompatibility. Biomaterials 2008, 29, 2941-2953. [CrossRef] [PubMed]

68. Bélanger, M.C.; Marois, Y. Hemocompatibility, biocompatibility, inflammatory and in vivo studies of primary reference materials low-density polyethylene and polydimethylsiloxane: A review. J. Biomed. Mater. Res. Appl. Biomater. 2001, 58, 467-477. [CrossRef] [PubMed]

69. Leclerc, E.; Sakai, Y.; Fujii, T. Cell Culture in 3-Dimensional Microfluidic Structure of PDMS (polydimethylsiloxane). Biomed. Microdevices 2003, 5, 109-114. [CrossRef]

70. Regehr, K.J.; Domenech, M.; Koepsel, J.T.; Carver, K.C.; Ellison-Zelski, S.J.; Murphy, W.L.; Schuler, L.A.; Alarid, E.T.; Beebe, D.J. Biological implications of polydimethylsiloxane-based microfluidic cell culture. Lab Chip 2009, 9, 2132-2139. [CrossRef] [PubMed]

71. Toepke, M.W.; Beebe, D.J. PDMS absorption of small molecules and consequences in microfluidic applications. Lab Chip 2006, 6, 1484-1486. [CrossRef] [PubMed]

72. Modena, M.M.; Chawla, K.; Misun, P.M.; Hierlemann, A. Smart Cell Culture Systems: Integration of Sensors and Actuators into Microphysiological Systems. ACS Chem. Biol. 2018, 13, 1767-1784. [CrossRef] [PubMed]

73. Mannino, R.G.; Qiu, Y.; Lam, W.A. Endothelial cell culture in microfluidic devices for investigating microvascular processes. Biomicrofluidics 2018, 12, 042203. [CrossRef] [PubMed]

74. Bein, A.; Shin, W.; Jalili-Firoozinezhad, S.; Park, M.H.; Sontheimer-Phelps, A.; Tovaglieri, A.; Chalkiadaki, A.; Kim, H.J.; Ingber, D.E. Microfluidic Organ-on-a-Chip Models of Human Intestine. Cell. Mol. Gastroenterol. Hepatol. 2018, 5, 659-668. [CrossRef] [PubMed]

75. Kaushik, G.; Leijten, J.; Khademhosseini, A. Concise Review: Organ Engineering: Design, Technology, and Integration. Stem Cells 2016, 35, 51-60. [CrossRef] [PubMed]

(C) 2018 by the authors. Licensee MDPI, Basel, Switzerland. This article is an open access article distributed under the terms and conditions of the Creative Commons Attribution (CC BY) license (http:/ / creativecommons.org/licenses/by/4.0/). 